\section{Cureus}

Received 05/20/2019

Review began 05/31/2019

Review ended 08/11/2019

Published 08/24/2019

\section{(c) Copyright 2019}

Patel et al. This is an open access article distributed under the terms of the Creative Commons Attribution License CC-BY 3.0., which permits unrestricted use, distribution, and reproduction in any medium, provided the original author and source are credited.

\title{
Lupus and the Liver: A Case Study
}

Shaan Patel ${ }^{1}$, Michelle Demory Beckler ${ }^{2}$, Marc M. Kesselman ${ }^{3}$

1. Miscellaneous, Nova Southeastern University Dr. Kiran C. Patel College of Osteopathic Medicine, Fort Lauderdale, USA 2. Immunology, Nova Southeastern University Dr. Kiran C. Patel College of Osteopathic Medicine, Fort Lauderdale, USA 3. Rheumatology, Dr. Kiran C. Patel College of Osteopathic Medicine, Nova Southeastern University, Davie, USA

Corresponding author: Shaan Patel, sp942@mynsu.nova.edu

\section{Abstract}

Systemic lupus erythematosus (SLE) is an autoimmune disorder with a wide range of systemic manifestations. Though skin, renal, joint, and hematologic involvement are often associated with SLE, hepatitis is not a common manifestation. While clinically significant hepatopathy in SLE is rare, asymptomatic hypertransaminasemia has been seen in up to 60 percent of SLE patients during the course of their disease and is generally attributed to viral hepatitis, hepatotoxic drugs, or alcohol use. A diagnosis of lupus hepatitis is largely considered a diagnosis of exclusion. There has been a correlation between the presence of ribosomal $\mathrm{P}$ autoantibodies with the incidence of lupus hepatitis. Generally, lupus hepatitis responds well to therapy with prednisone, although cases refractory to corticosteroids and conventional immunosuppressants have been described. In these cases, treatment with mycophenolate mofetil has been shown to be effective. Here, we present the case of a 15-year old female who presented with a new diagnosis of SLE with an incidental elevation of her liver function tests (LFTs) and a subsequent finding of hepatomegaly with fatty infiltration.

Categories: Internal Medicine, Rheumatology

Keywords: lupus hepatitis, systemic lupus erythematosus (sle), systemic lupus erythematosus (sle), lupus

\section{Introduction}

Systemic lupus erythematosus (SLE) is an autoimmune disorder classically associated with malar rash, arthralgias, cytopenias, serositis, renal failure, endocarditis, and antiphospholipid syndrome [1]. However, with the pathophysiology of the disease being based in the production of antinuclear antibodies (ANA) and antibodies against various components of the nucleus, lupus can manifest in nearly any organ system in the body and thus can have a wide range of presenting symptoms [2]. One possible manifestation of SLE is an elevation of liver function tests (LFTs) which, as will be discussed here, can be due to a wide variety of etiologies including the SLE itself [3].

\section{Case Presentation}

A 15-year old African American female patient with history of recurrent episodes of eyelid swelling presented to the Emergency Department (ED) with a one-week history of bilateral eyelid swelling and an erythematous rash on her face. She reported an elevated temperature at home with a maximum temperature of $104 \circ \mathrm{F}$ the day prior to admission, for which she took ibuprofen. Of note, this was her third episode of eyelid swelling in the past year. Previous episodes had resolved with a five-day course of prednisone. However, during this instance while her swelling improved with corticosteroids, her rash presented and worsened leading to the ED visit. The patient had no known allergies, no past medical or surgical history, and was 
up to date on her immunizations. She also denied any tobacco, alcohol, or illicit substance use and had never been sexually active. On examination, the patient was afebrile, normotensive, with an oxygen saturation of 98 percent on room air and a body mass index (BMI) of 22.9. She was alert, awake, and oriented to person, place, and time. The patient had bilateral eyelid edema, facial edema, an erythematous, nonpruritic, non-tender rash in a malar distribution along the nasolabial folds, cervical and submandibular lymphadenopathy, and oval black discoid erythematous patches along right upper arm. Physical examination was otherwise unremarkable.

Labs were remarkable for an elevated erythrocyte sedimentation rate (ESR) of $46 \mathrm{~mm} / \mathrm{hr}$ and hemoglobin $(\mathrm{Hb})$ of $11 \mathrm{~g} / \mathrm{dL}$ along with a hypertransaminasemia with aspartate transaminase (AST) and alanine transaminase (ALT) of 154 units/liter and 145 units/liter, respectively (Table 1,4). Serologies were positive for antinuclear antibodies, anti-Smith, anti-ribonucleoprotein (RNP), anti-chromatin (nucleosomal). She was negative for anti-smooth muscle antibody, antimitochondrial, anti-dsDNA, anti-Liver Kidney Microsomal type 1 (LKM1), and antiphospholipid antibody serologies along with a negative hepatitis panel. Monospot, Ebstein-Barr virus (EBV) and cytomegalovirus (CMV) IgM were all negative (Table 2, 3). However, EBV IgG levels were elevated (Table 3). Total IgG and IgE levels were elevated, as well as elevated levels of ferritin, amylase, aldolase, C1 esterase inhibitor with normal levels of C3 and C4 (Table 4). Additionally, acetaminophen, salicylate, and ethanol levels were all low (Table 4). Based on serologies, a diagnosis of SLE was made. An ultrasound evaluation of her liver performed subsequently found fatty infiltration and hepatomegaly (Figure 1). Patient's symptoms showed improvement once started on methylprednisolone 40mg twice daily and hydroxychloroquine 200mg daily and repeat LFTs showed downtrend with an AST and ALT of 114 units/liter and 137 units/liter, respectively. After discharge from the hospital, she was told to follow-up with the Pediatric Rheumatology outpatient. 


\section{Cureus}

\begin{tabular}{lll}
\hline Lab & Result & Reference Range \\
\hline White Blood Cells (WBC) & $5.23 \times 10^{\wedge} 3 \mathrm{WBC} / \mathrm{uL}$ & $4.5-13 \times 10^{\wedge} 3 \mathrm{WBC} / \mathrm{uL}$ \\
\hline Hemoglobin (Hb) & $11.0 \mathrm{~g} / \mathrm{dL}$ & $11.5-15.3 \mathrm{~g} / \mathrm{dL}$ \\
\hline Mean Corpuscular Volume (MCV) & $86.2 \mathrm{fl}$ & $78-100 \mathrm{fl}$ \\
Platelets (PIt) & $172 \times 10^{\wedge} 3 \mathrm{Plt} / \mathrm{uL}$ & $140-400 \times 10^{\wedge} 3 \mathrm{Plt} / \mathrm{uL}$ \\
\hline Blood Urea Nitrogen (BUN) & $5 \mathrm{mg} / \mathrm{dL}$ & $7-19 \mathrm{mg} / \mathrm{dL}$ \\
\hline Creatinine (Cr) & $0.8 \mathrm{mg} / \mathrm{dL}$ & $0.6-1.1 \mathrm{mg} / \mathrm{dL}$ \\
Alkaline Phosphatase (ALP) & $71 \mathrm{units} / \mathrm{L}$ & $40-150 \mathrm{units} / \mathrm{L}$ \\
Aspartate Aminotransferase (AST) & $154 \mathrm{units} / \mathrm{L}$ & $5-34 \mathrm{units} / \mathrm{L}$ \\
Alanine Aminotransferase (ALT) & $145 \mathrm{units} / \mathrm{L}$ & $0-55 \mathrm{units} / \mathrm{L}$
\end{tabular}

\section{TABLE 1: Pertinent Complete Blood Count and Comprehensive Metabolic Panel}

Values

Abbreviations:

uL (microliter)

$\mathrm{dL}$ (deciliter)

L (liter)

mg (milligram)

g (gram)

fl (femtoliters)

mmol (millimoles) 


\section{Cureus}

\section{Lab}

Antinuclear Antibody (ANA)

Anti-Smith

Anti-RNP

Anti-chromatin (nucleosomal)

C1 esterase inhibitor

Anti-Smooth Muscle

Anti-Mitochondrial

Anti-LKM1

Anti-dsDNA

Anticardiolipin IgM

Anticardiolipin IgG

Anti-Beta 2 glycoprotein IgM

Anti-Beta 2 glycoprotein IgG

Angiotensin Converting Enzyme (ACE)
Result

Positive

$3.3 \mathrm{Al}$

$6.7 \mathrm{Al}$

$1.3 \mathrm{Al}$

$59 \mathrm{mg} / \mathrm{dL}$

Negative

Negative

$<36$ units $/ \mathrm{mL}$

$<1 \mathrm{IU} / \mathrm{mL}$

$<12 \mathrm{mpl}$

$<14 \mathrm{gpl}$

$<9 \mathrm{SMU}$

$<9$ SGU

65 units/L

\section{Reference Range}

Negative

$<1.0 \mathrm{Al}$

$<1.0 \mathrm{Al}$

$<1.0 \mathrm{Al}$

$21-39 \mathrm{mg} / \mathrm{dL}$

Negative

Negative

$<36$ units $/ \mathrm{mL}$

$<4 \mathrm{IU} / \mathrm{mL}$

$<12 \mathrm{mpl}$

$<14 \mathrm{gpl}$

$<20 \mathrm{SMU}$

$<20$ SGU

13-100 units/L

\section{TABLE 2: Positive and Pertinent Negative Serologies}

$\mathrm{mg}$ (milligrams)

dl (deciliters)

$\mathrm{mL}$ (milliliters)

IU (international units) 


\section{Cureus}

\begin{tabular}{lll}
\hline Lab & Result & Reference Range \\
\hline Hepatitis B Surface Antigen (HBsAg) & Non-reactive & Non-reactive \\
Hepatitis B Core Antibody IgM & Non-reactive & Non-reactive \\
Anti-Hepatitis A Virus IgM & Non-reactive & Non-reactive \\
Anti-Hepatitis C Virus IgM & Non-reactive & Non-reactive \\
EBV Early Antigen D IgG & 11.6 units $/ \mathrm{mL}$ & $<9$ units $/ \mathrm{mL}$ \\
EBV Nuclear Antigen IgG & 313 units $/ \mathrm{mL}$ & $<18$ units $/ \mathrm{mL}$ \\
EBV Viral Capsid Antigen IgG & 387 units $/ \mathrm{mL}$ & $<18$ units $/ \mathrm{mL}$ \\
EBV Viral Capsid Antigen IgM & $<36$ units $/ \mathrm{mL}$ & $<36$ units $/ \mathrm{mL}$ \\
Monospot & Negative & Negative \\
CMV IgM & 0.59 units $/ \mathrm{mL}$ & $<0.9$ units $/ \mathrm{mL}$
\end{tabular}

\section{TABLE 3: Viral Serologies}

$\mathrm{mL}$ (milliliters) 


\section{Cureus}

\begin{tabular}{lll}
\hline Lab & Result & Reference Range \\
\hline Erythrocyte Sedimentation Rate (ESR) & $46 \mathrm{~mm} / \mathrm{hr}$ & $0-10 \mathrm{~mm} / \mathrm{hr}$ \\
\hline IgG Level & $2318 \mathrm{mg} / \mathrm{dL}$ & $552-1631 \mathrm{mg} / \mathrm{dL}$ \\
IgE Level & $1318 \mathrm{kU} / \mathrm{L}$ & $<114 \mathrm{kU} / \mathrm{L}$ \\
Ferritin & $846 \mathrm{ng} / \mathrm{dL}$ & $5-204 \mathrm{ng} / \mathrm{dL}$ \\
Amylase & $386 \mathrm{units} / \mathrm{L}$ & $25-125 \mathrm{units} / \mathrm{L}$ \\
C3 & $126 \mathrm{mg} / \mathrm{dL}$ & $83-193 \mathrm{mg} / \mathrm{dL}$ \\
C4 & $22 \mathrm{mg} / \mathrm{dL}$ & $15-57 \mathrm{mg} / \mathrm{dL}$ \\
Acetaminophen Level & $<3 \mathrm{mcg} / \mathrm{mL}$ & $10-30 \mathrm{mcg} / \mathrm{mL}$ \\
Salicylate Level & $<5 \mathrm{mg} / \mathrm{dL}$ & $15-30 \mathrm{mg} / \mathrm{dL}$ \\
Ethanol Level & $<10 \mathrm{mg} / \mathrm{dL}$ & $<10 \mathrm{mg} / \mathrm{dL}$
\end{tabular}

\section{TABLE 4: Miscellaneous Labs}

$\mathrm{mm}$ (millimeter)

hr (hour)

mcg (microgram)

ng (nanogram)

mg (milligram)

$\mathrm{mL}$ (milliliter)

$\mathrm{dL}$ (deciliter)

L (liter)

$\mathrm{kU}$ (kilounits) 


\section{Cureus}

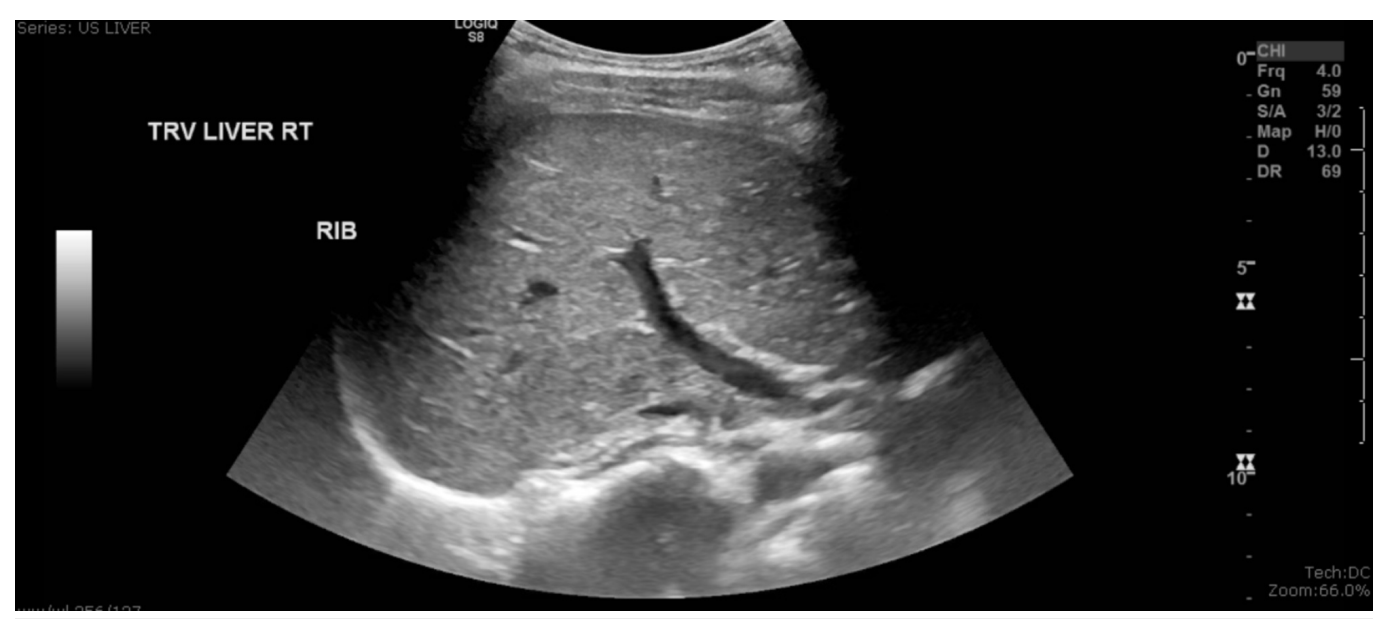

FIGURE 1: Ultrasound Image of Liver, Right Side Transverse View

\section{Discussion}

Based on the underlying etiology, the differential for liver manifestations in a patient with SLE can be categorized as due to non-immunological comorbidities, an overlap of another immunological syndrome, or lupus hepatitis [3]. Liver function test abnormalities have been described during some point of the disease course in up to 60 percent of SLE patients. However, it is usually attributed to non-immunological etiologies such as prior treatment with hepatotoxic drugs, viral hepatitis, or alcohol use [4]. Diagnosing lupus hepatitis as the cause of liver damage is challenging as it may be attributed to another co-existing autoimmune etiology such as Autoimmune Hepatitis (AIH) or Primary Biliary Cirrhosis (PBC) [3]. Another consideration is that $\mathrm{AIH}$, which used to be known as lupoid hepatitis, can present with extrahepatic manifestations such as arthralgias and thus be mistaken for SLE [5]. The liver damage can also be due to the lupus itself, which would be known as lupus hepatitis [3]. Having a schema for classifying the differential of liver damage in a SLE patient is important to not only guide the workup but also in the case of our patient, as diagnosis of lupus hepatitis requires exclusion of all other etiologies.

Bessone, et al. describe lupus hepatitis as a subclinical hepatopathy with asymptomatic elevations in liver enzymes that usually occur in the setting of an active lupus flare [3]. As mentioned, the diagnosis of lupus hepatitis can be difficult due to the large variety of etiologies of liver damage associated with lupus. Further complicating the diagnosis, the liver pathology in lupus hepatitis patients tends to be non-specific [4]. As a result, lupus hepatitis requires viral serologies, autoimmune panels, and other exclusionary testing to be done to rule out other etiologies [3]. As can be expected from the ambiguity in differentiating lupus hepatitis from other etiologies, finding an exact incidence in the literature can be challenging with a large variety in reported incidences [3]. However, one recent study by Zheng, et al., of 504 SLE patients found that the incidence of lupus hepatitis based on the exclusion of all other liver etiologies was 9.3 percent with a higher prevalence in those patients with active SLE [6].

Recent research into liver damage in SLE patients found the presence of different markers that could serve as potential diagnostic markers in the future. The first of these markers and the one that has been most widely studied is the presence of ribosomal P autoantibodies [7]. While positive ribosomal $\mathrm{P}$ autoantibody titers are present in up to 30 percent of SLE patients, the presence of positive titers have been found in up to 70 percent of SLE patients with lupus hepatitis $[8,9]$. Additionally, this value is significant when compared to the proportion of 
positive ribosomal $\mathrm{P}$ autoantibody titers found in SLE patients with other etiologies of liver damage, such as 17 percent in drug-induced hepatitis and 20 percent in patients with SLE-AIH overlap [9]. Furthermore, positive titers of ribosomal P autoantibody are associated with neuropsychiatric manifestations [10]. It is hypothesized that these autoantibodies are not simply a marker of the disease, but may also be responsible for the underlying pathophysiology of the liver disease by possibly targeting hepatoma cell membrane proteins and upregulating proinflammatory cytokines, ultimately leading to hepatocellular lysis [11, 12]. In one study, immunofluorescence found the presence of epitopes that are antigenically similar to P-proteins on the surface of human hepatoma cells, neuroblastoma cells, and fibroblasts [10]. One other diagnostic modality that may provide a way to differentiate lupus from other liver diseases in the future is the deposit of complement 1q in the liver [6]. Zheng, et al. found that seven out of ten of their lupus hepatitis patients that underwent liver biopsy were positive for intense deposits of complement 1q seen on immunopathology compared to no deposits of complement $1 \mathrm{q}$ in patients with other forms of liver disease [6].

Corticosteroids have been found to be an effective treatment modality for lupus hepatitis and a study by Piga, et al. found that the disease generally responds well to moderate to high doses of prednisone with resolution of the disease course [2]. One study by Tagawa, et al. discussed a case of lupus hepatitis that was refractory not only to corticosteroids but also to conventional immunosuppressants such as cyclophosphamide, tacrolimus, and azathioprine [11]. In this case, Tagawa, et al. found that utilizing mycophenolate mofetil led to rapid stabilization and resolution of liver enzyme abnormalities and control of the lupus hepatitis activity despite reduction in methylprednisone dose [11].

\section{Conclusions}

This case demonstrates a unique presentation of SLE with lupus hepatitis. While elevation of LFTs with evidence of hepatic steatosis can be quite common in patients with lupus, this patient is a rare case where one can effectively rule out all other etiologies due to no history of alcohol use, normal BMI, a negative hepatitis panel with negative EBV and CMV IgM, negative anti-smooth muscle, anti-LKM1, and anti-mitochondrial serology, and low levels of acetaminophen, salicylates, and ethanol. Furthermore, the treatment of a patient with a new diagnosis of SLE allows us to rule out the effect of chronic treatment of SLE with hepatotoxic drugs causing the liver damage. While lupus hepatitis is a rare presentation of lupus, it is important to note that it responds well to corticosteroids and in our case LFTs began to downtrend several days after beginning treatment with methylprednisolone.

\section{Additional Information}

\section{Disclosures}

Human subjects: Consent was obtained by all participants in this study. Conflicts of interest: In compliance with the ICMJE uniform disclosure form, all authors declare the following: Payment/services info: All authors have declared that no financial support was received from any organization for the submitted work. Financial relationships: All authors have declared that they have no financial relationships at present or within the previous three years with any organizations that might have an interest in the submitted work. Other relationships: All authors have declared that there are no other relationships or activities that could appear to have influenced the submitted work.

\section{References}

1. Cojocaru M, Cojocaru IM, Silosi I, Vrabie CD: Manifestations of systemic lupus erythematosus . Maedica (Buchar). 2011, 6:330-336.

2. Piga M, Vacca A, Porru G, Cauli A, Mathieu A: Liver involvement in systemic lupus 
erythematosus: incidence, clinical course and outcome of lupus hepatitis. Clin Exp Rheumatol. 2010, 28:504-510.

3. Bessone F, Poles N, Roma MG: Challenge of liver disease in systemic lupus erythematosus: Clues for diagnosis and hints for pathogenesis. World J Hepatol. 2014, 6:394-409.

10.4254/wjh.v6.i6.394

4. Runyon BA, LaBrecque DR, Anuras S: The spectrum of liver disease in systemic lupus erythematosus. Report of 33 histologically-proved cases and review of the literature. Am J Med. 1980, 69:187-194.

5. Beisel C, Weiler-Normann C, Teufel A, Lohse AW: Association of autoimmune hepatitis and systemic lupus erythematodes: a case series and review of the literature. World J Gastroenterol. 2014, 20:12662-12667. 10.3748/wjg.v20.i35.12662

6. Zheng RH, Wang JH, Wang SB, Chen J, Guan WM, Chen MH: Clinical and immunopathological features of patients with lupus hepatitis. Chin Med J. 2013, 2:260-266.

7. Carmona-Fernandes D, Santos MJ, Canhão H, Fonseca JE: Anti-ribosomal P protein IgG autoantibodies in patients with systemic lupus erythematosus: diagnostic performance and clinical profile. BMC Med. 2013, 11 :98. 10.1186/1741-7015-11-98

8. Mahler M, Kessenbrock K, Szmyrka M, et al.: International multicenter evaluation of autoantibodies to ribosomal P proteins. . Clin Vaccine Immunol. 2006, 13:77-83. 10.1128/CVI.13.1.77-83.2006

9. Ohira H, Takiguchi J, Rai T, et al.: High frequency of anti-ribosomal P antibody in patients with systemic lupus erythematosus-associated hepatitis. Hepatol Res. 2004, 28:137-139.

10.1016/j.hepres.2003.11.008

10. Koren E, Reichlin MW, Koscec M, Fugate RD, Reichlin M: Autoantibodies to the ribosomal P proteins react with a plasma membrane-related target on human cells. J Clin Invest. 1992, 89:1236-1241. 10.1172/JCI115707

11. Tagawa Y, Saito, T, et al.: Successful treatment of severe refractory lupus hepatitis with mycophenolate mofetil. Lupus. 25:543-546. 10.1177/0961203315625118

12. Nagai T, Arinuma Y, Yanagida T, Yamamoto K, Hirohata S: Anti-ribosomal P protein antibody in human systemic lupus erythematosus up-regulates the expression of proinflammatory cytokines by human peripheral blood monocytes. Arthritis Rheum. 2005, 52:847-855. 10.1002/art.20869 